بررسى اثرات تغيير كاربرى اراضى بر سيلخيزى و رسوبزايـى حاربي حوزه آبخيز حنيفقان، فارس ارسي سير

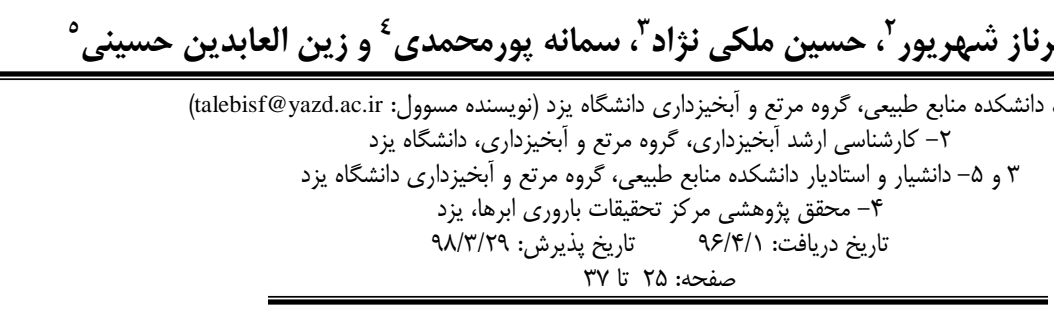

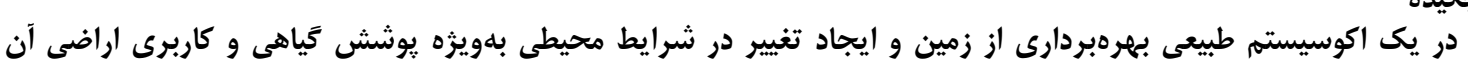

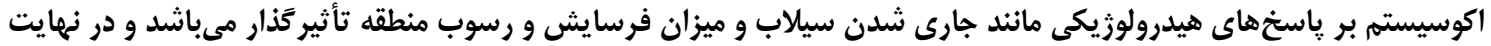

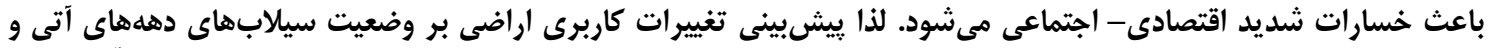

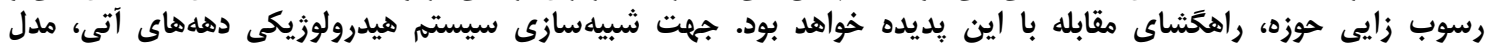

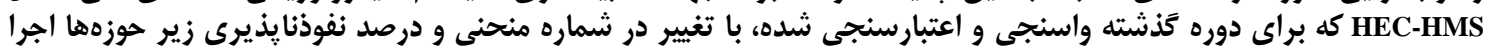

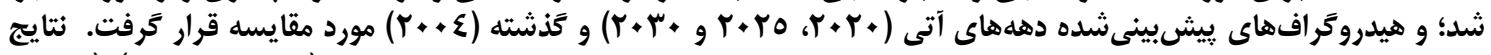

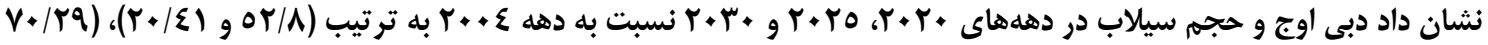

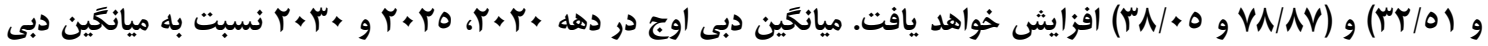

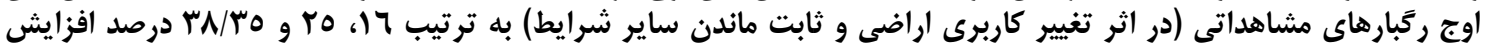

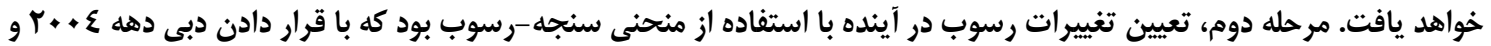

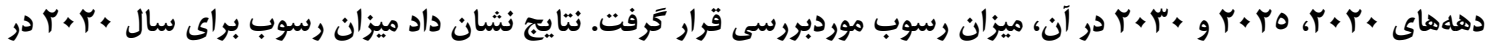

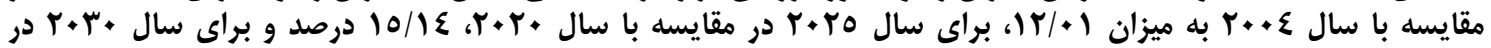

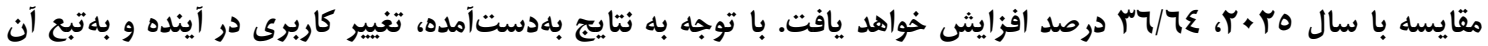

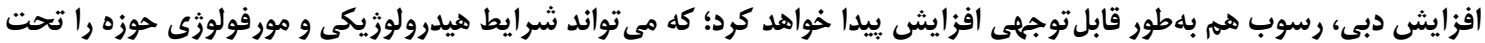
تأثير قرار دهد.

وازههاى كليدى: تغييركاربرى اراضى، رواناب، فرسايش، منحنى سنجه رسوب، واسنجى، HEC-HMS

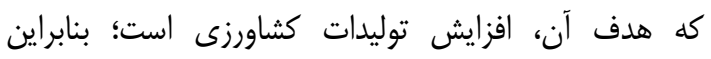

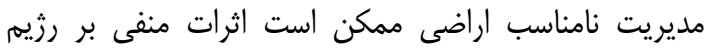

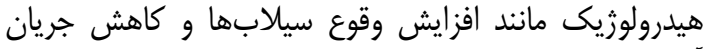

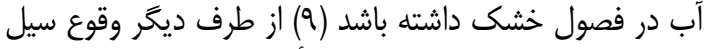

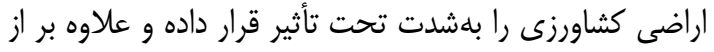

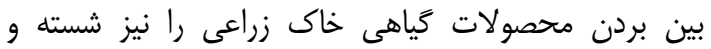

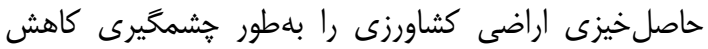

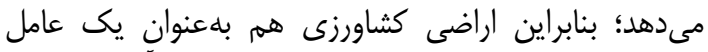

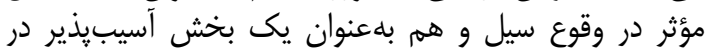
برابر سيل مطرح هستند.

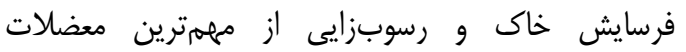

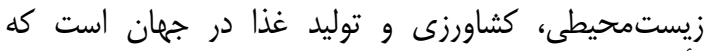

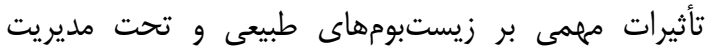

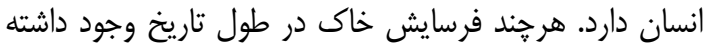

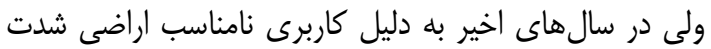

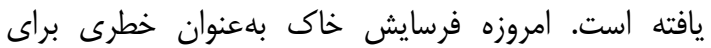

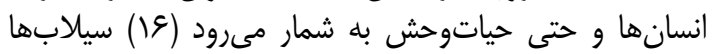

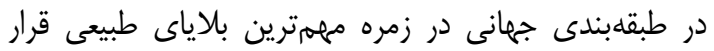

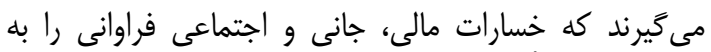

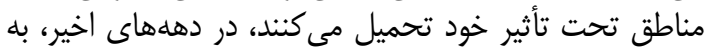

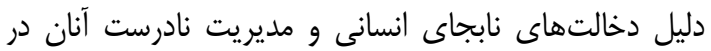

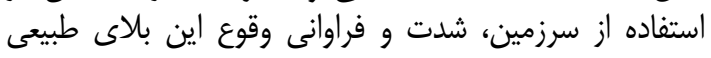

مقدمه

تغيير كاربرى زمين مىتواند تبديل از يك نوع كاربرى به به

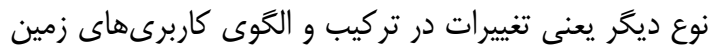

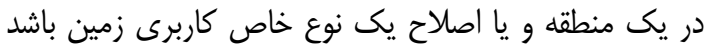

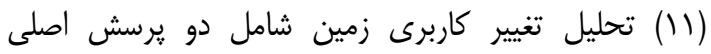

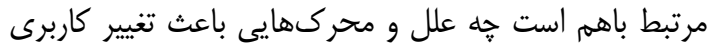

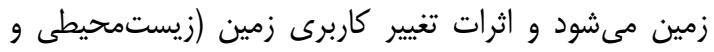

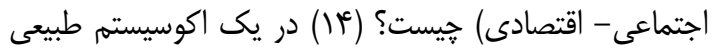

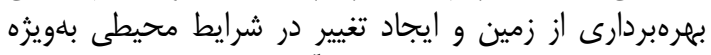

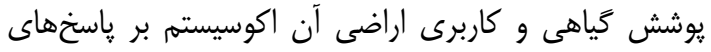

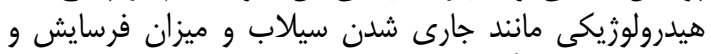

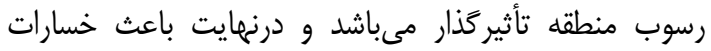

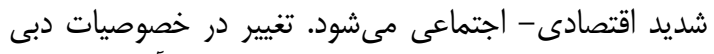

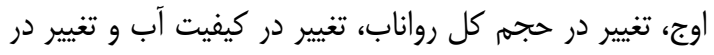

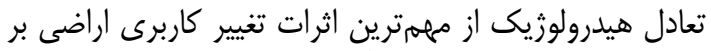

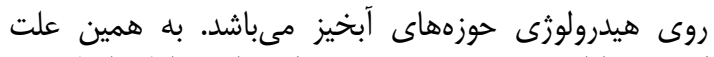

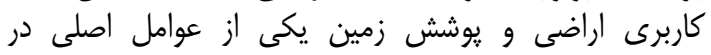

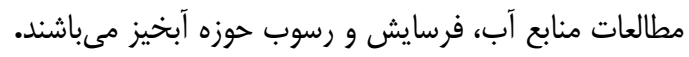

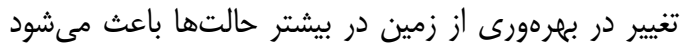

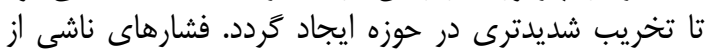

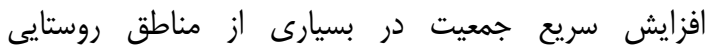
كشورهاى درحالتوسعه باعث تغيير كاربرى اراضى مى گردد 


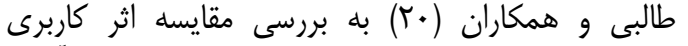

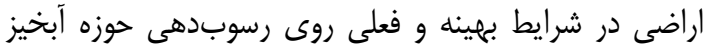

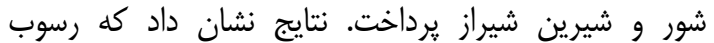

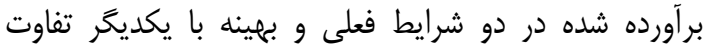

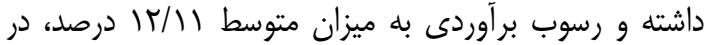

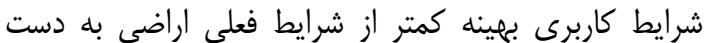

رحمانى (ه) ارزيابى تأثير تغيير كاربرى اراضى بر إنى

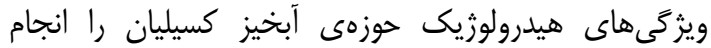

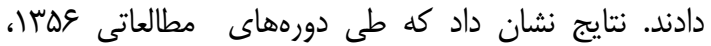

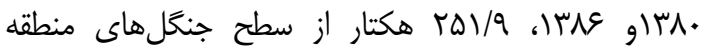

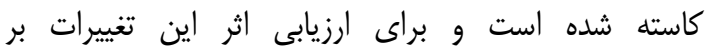

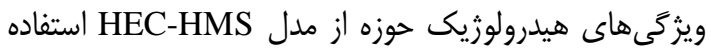

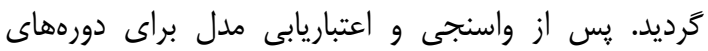

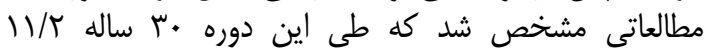
مترمكعب برثانيه به دبى اوج و

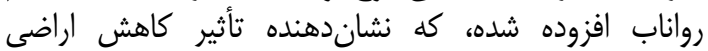

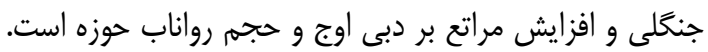

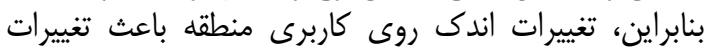

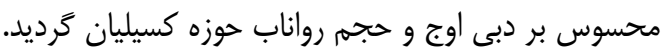

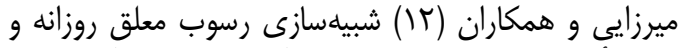

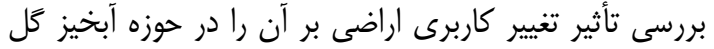

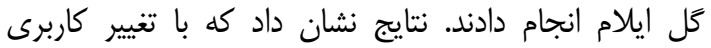

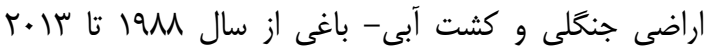

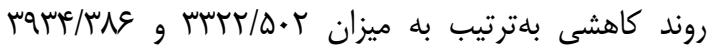

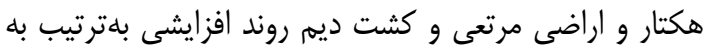

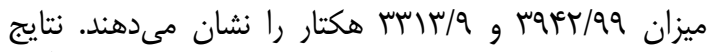

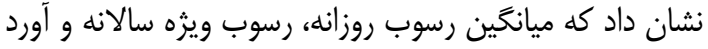

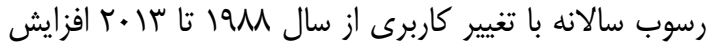
يافته است.

سوان ورا كامتورن (19) با استفاده از مدل هيدرولوزيكى أفي و و سيستم اطلاعات جغرافيايى، اثرات تغيير كاربرى

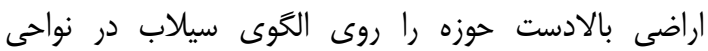

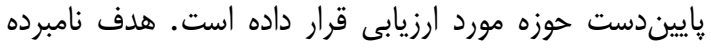

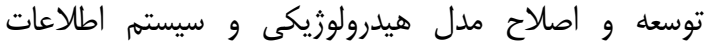

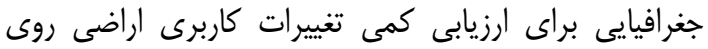

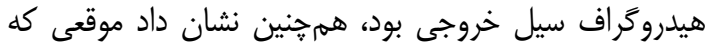

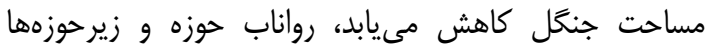
بيشتر مىشود.

زيمرمن و همكاران (T) اثردات

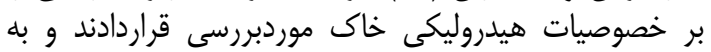

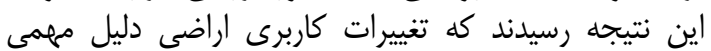

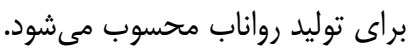

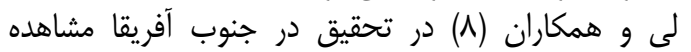

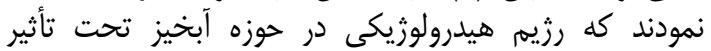

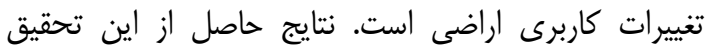

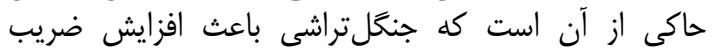

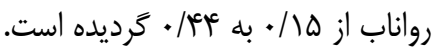

افزايشيافته است ((). تغيير كاربرى اراضى يكى از تغييرات

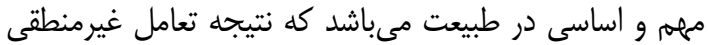

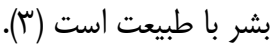

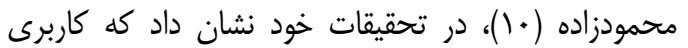

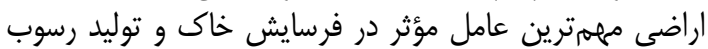

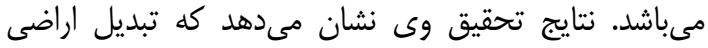

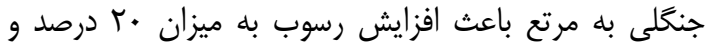

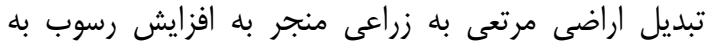

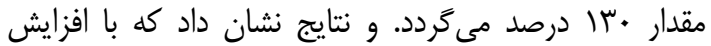

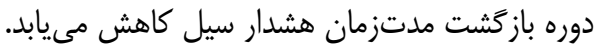

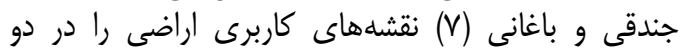

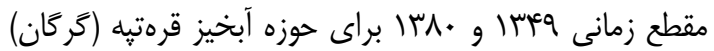

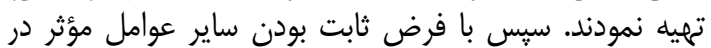

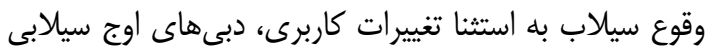

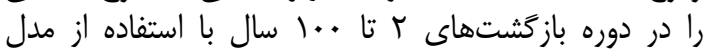

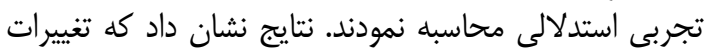

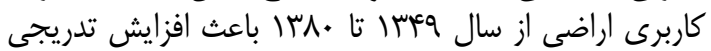

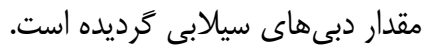

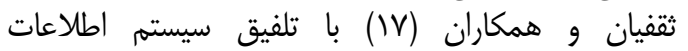

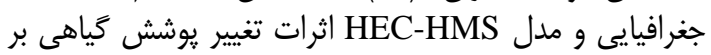

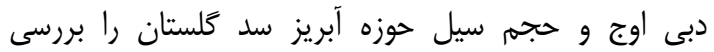

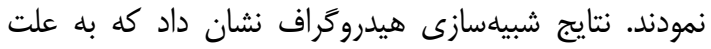

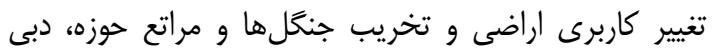

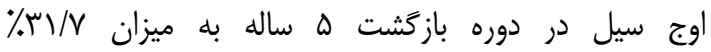
افزايشيافته است.

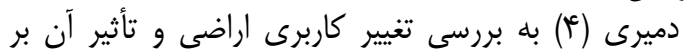

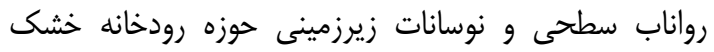

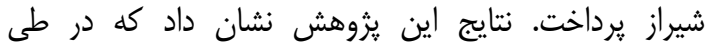

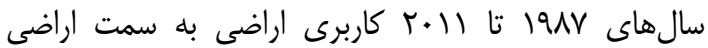

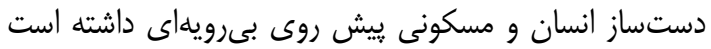

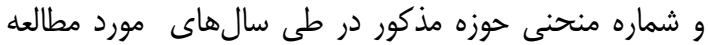

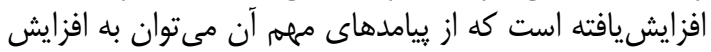
حجم و تعداد سيلابهاى روى روى إداده اشاره نمود.

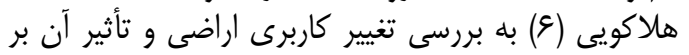

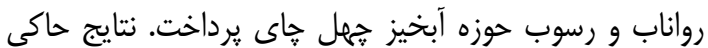

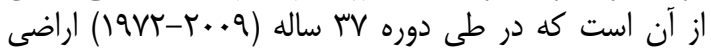

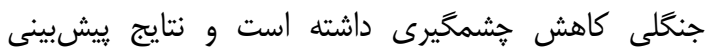

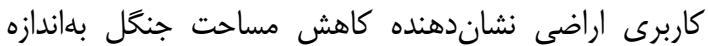

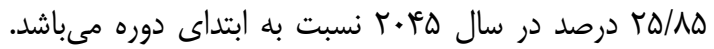

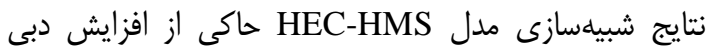

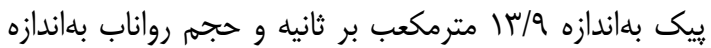

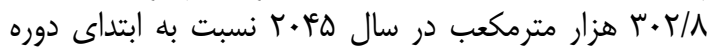

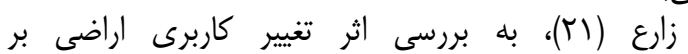

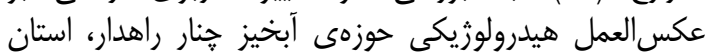

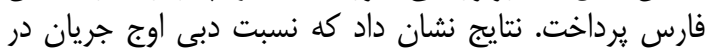

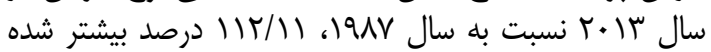

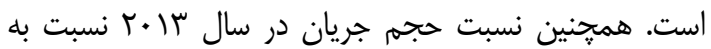

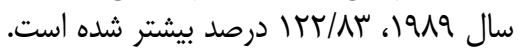


تنايج اين بررسى مى تواند اثرات كمى و كيفى تغيير كاربرى

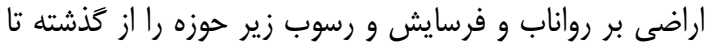

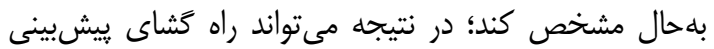

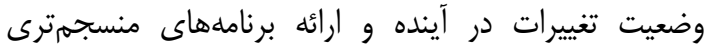

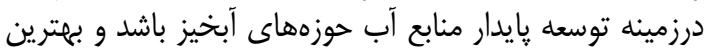

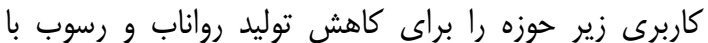
حفظ توسعه پايدار تعيين نمايد.

\section{مواد و روشها}

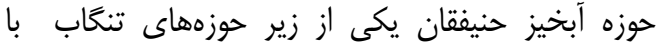

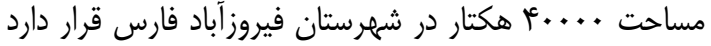

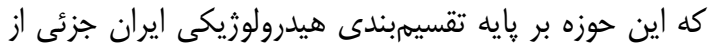

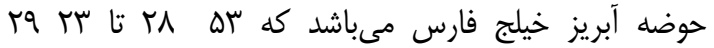

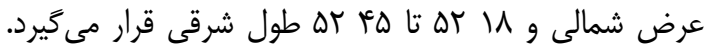

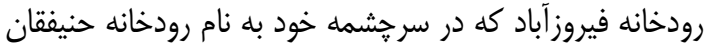

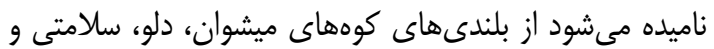

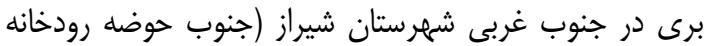

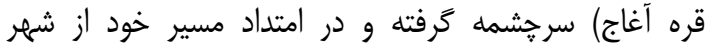

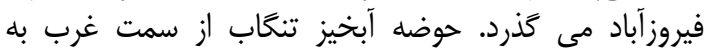

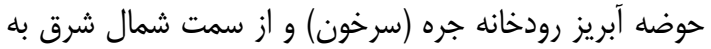

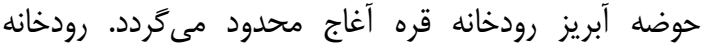

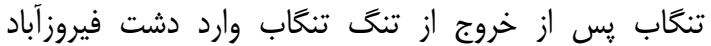

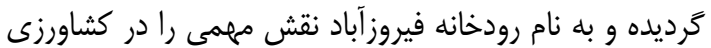

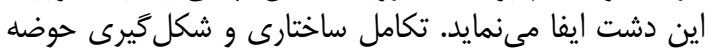

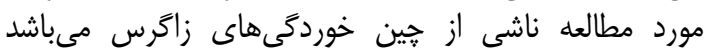

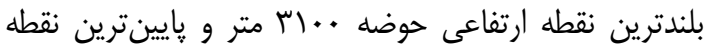

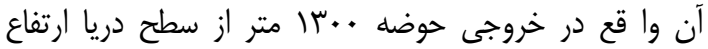
دارد. شكل (ا) مراحل كلى تحقيق را نشان مىدهد.

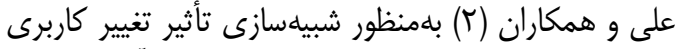

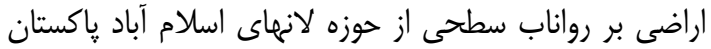

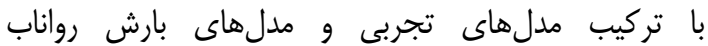
HEC-HMS

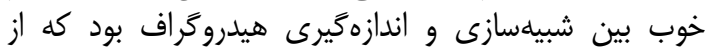

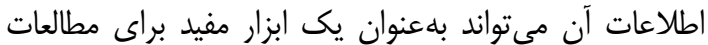

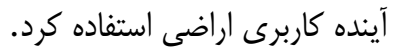

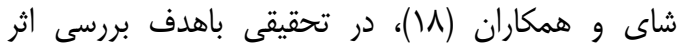

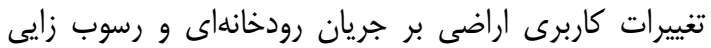

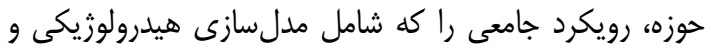

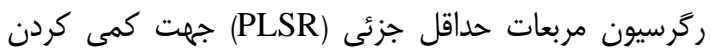

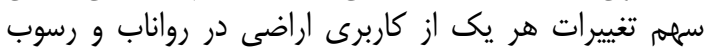

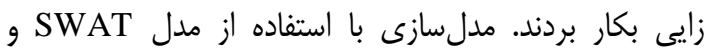

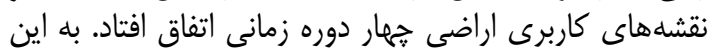

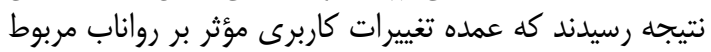

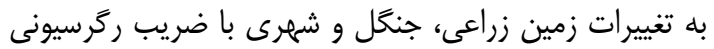

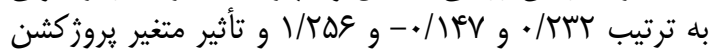

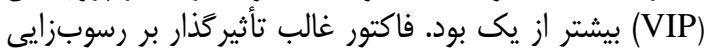

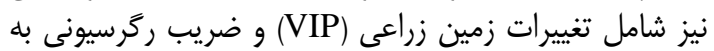

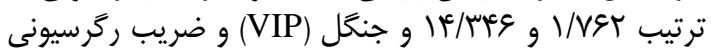

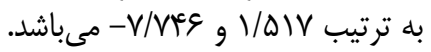

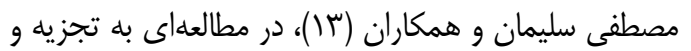

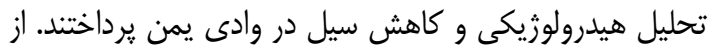

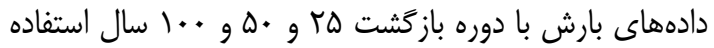

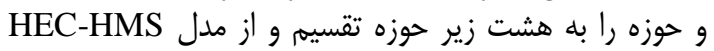

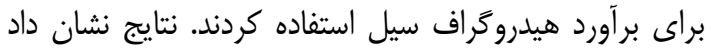

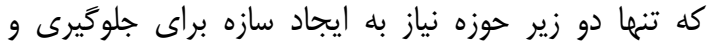

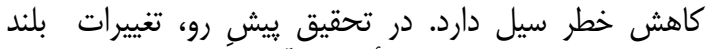

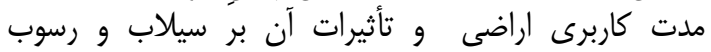
رودخانه، در حوزه آبخيز حنيفقان مورد بررسى قرار كرات 


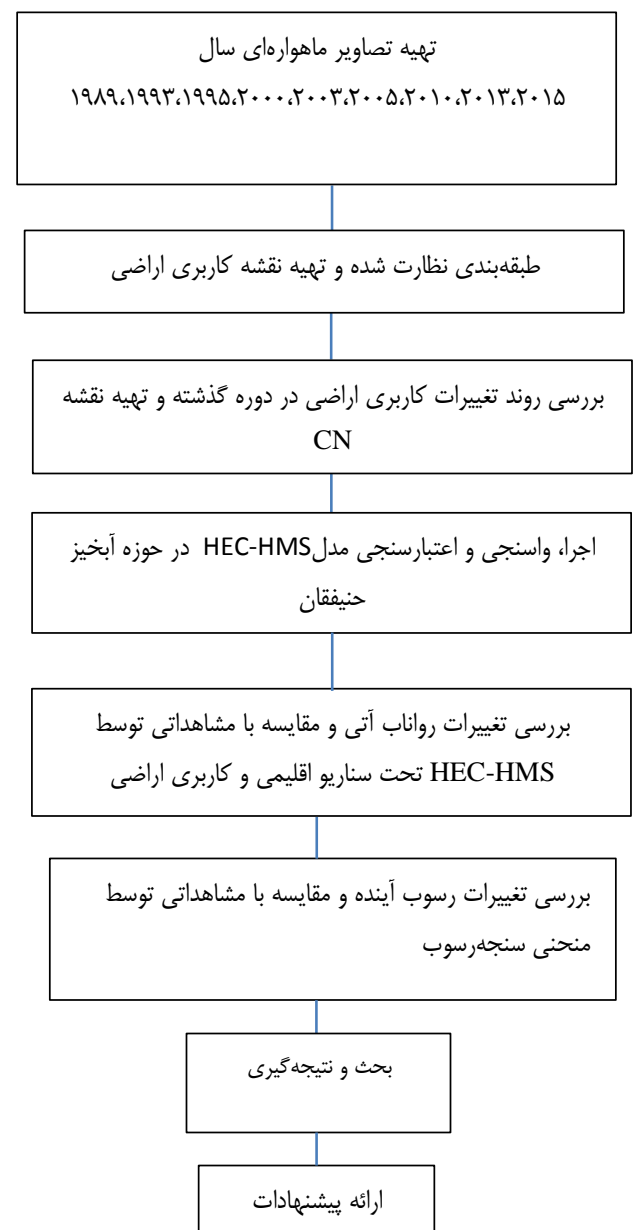

شكل 1- مر احل و نحوه انجام تحقيق

Figure 1. Steps and method of research

يارامترها را دارد. جهت انجام مطالعه ييش رو ازي ايستخاه

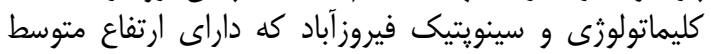

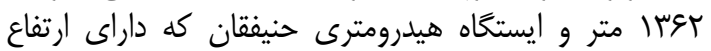

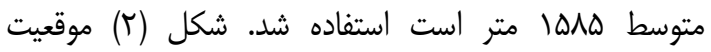

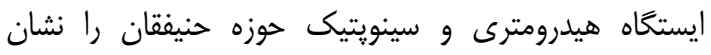

مدل HEC-HMS از انواع مدلهاى كامييوترى بوده كه

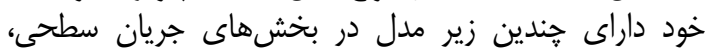

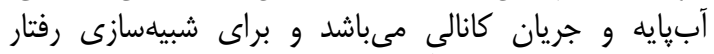

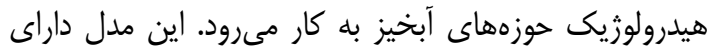

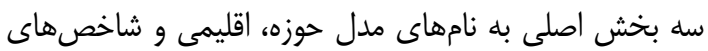

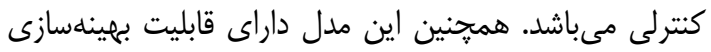

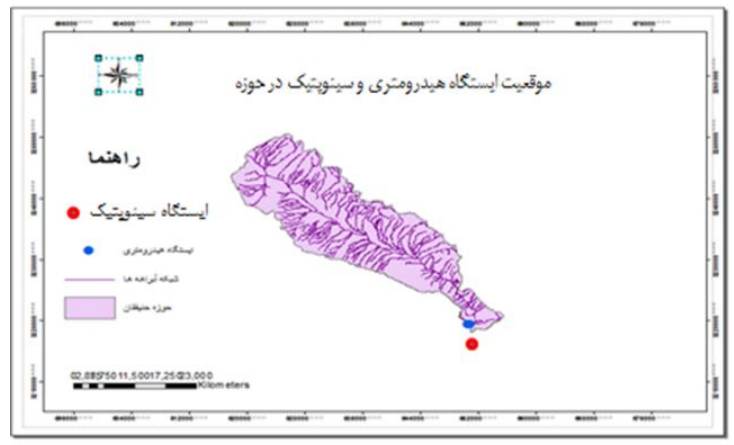

شكل r- موقعيت ايستخاه هيدرومترى و سينويتيك حوزه

Figure 2. Position of hydrometric and synoptic station of watershed 
مساحت كاربرىها و با درنظر گرفتن شرايط ثابت براى ساير مانب

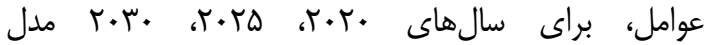

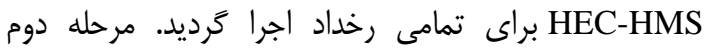

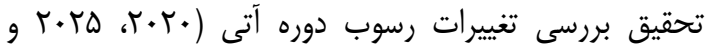

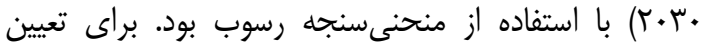
تغييرات رسوب آينده، از منحنى سنجه رسئ رسوب استفاده شد.

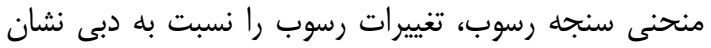

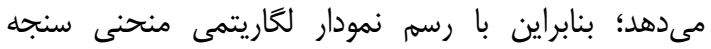

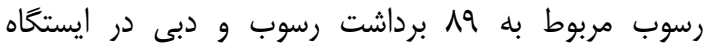

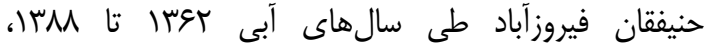

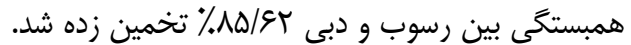

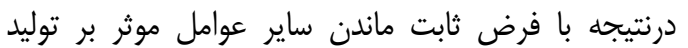

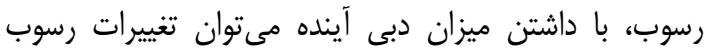
آينده را نسبت به حال مقايسه كرد.

\section{نتايج و بحث}

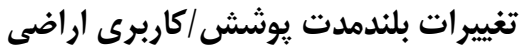

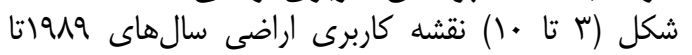

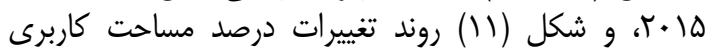
اراضى در دورههاى زمانى مطالعه شده را نشان مى دهندات

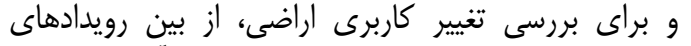

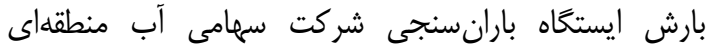
فارس واقع در شهر شيراز، 9 رويداد بارش دار داراى دبى ديى متناظر

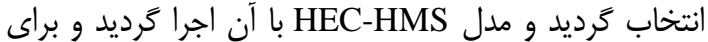

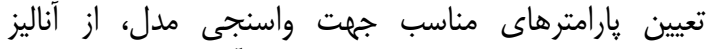

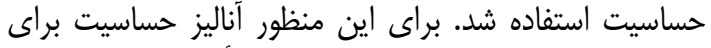

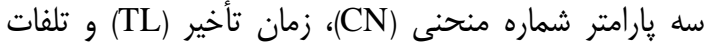

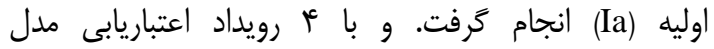
HEC-HMS

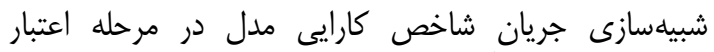

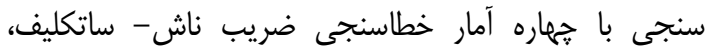

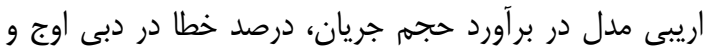

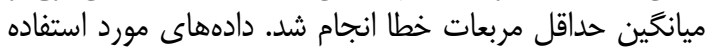

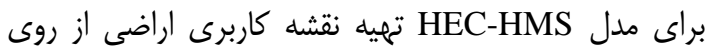

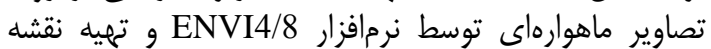

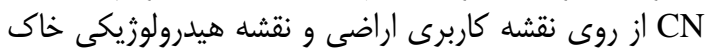

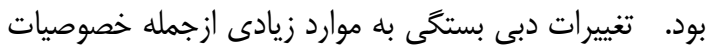

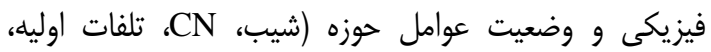

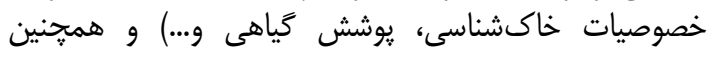

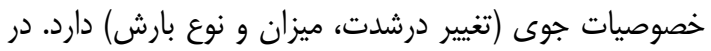

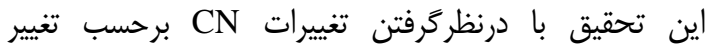

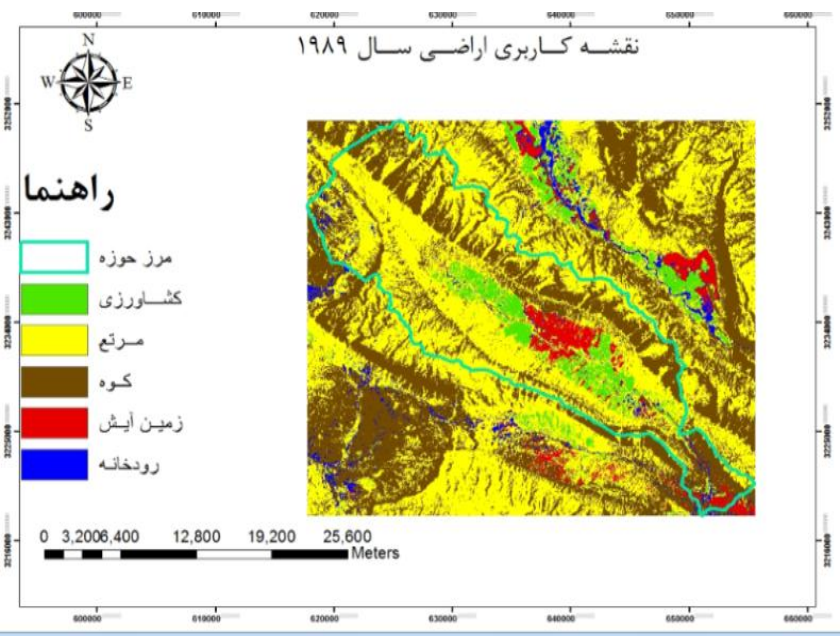

شكل r- نقشه كاربرى اراضى حوزه آبخيز حنيفقان فيروزآباد فارس در سال 1919

Figure 3. Land use map of the Honifaqan watershed of Firouzabad Fars in 1989 

بررسى اثرات تغيير كاربرى اراضى بر سيلخيزى و رسوبزايى حوزه آبخيز حنيفقان، فارس

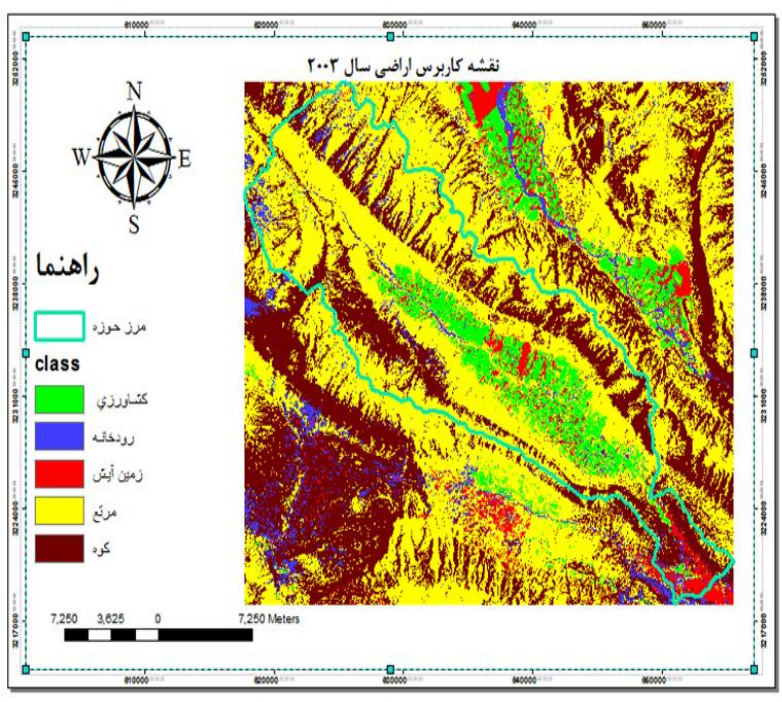

شكل צ- نقشه كاربرى اراضى حوزه آبخيز حنيفقان فيروزآباد فارس در

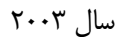

Figure 6. Land use map of the Honifaqan watershed of Firouzabad Fars in 2003

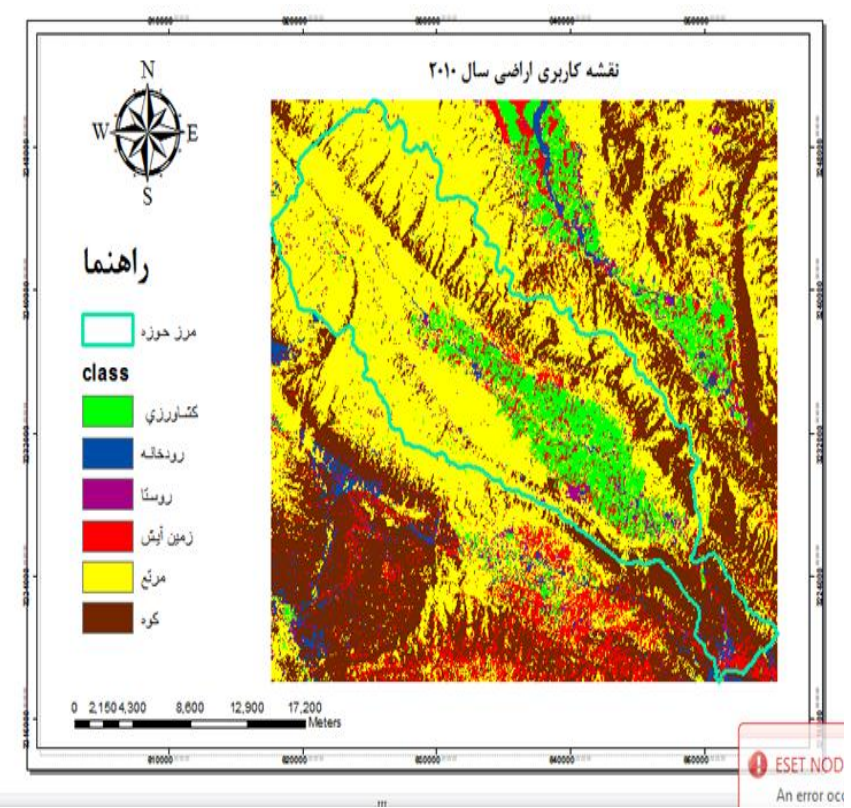

شكل ^- نقشه كاربرى اراضى حوزه آبخيز حنيفقان فيروزآباد فارس در r.l. • سال

Figure 8. Land use map of the Honifaqan watershed of Firouzabad Fars in 2010

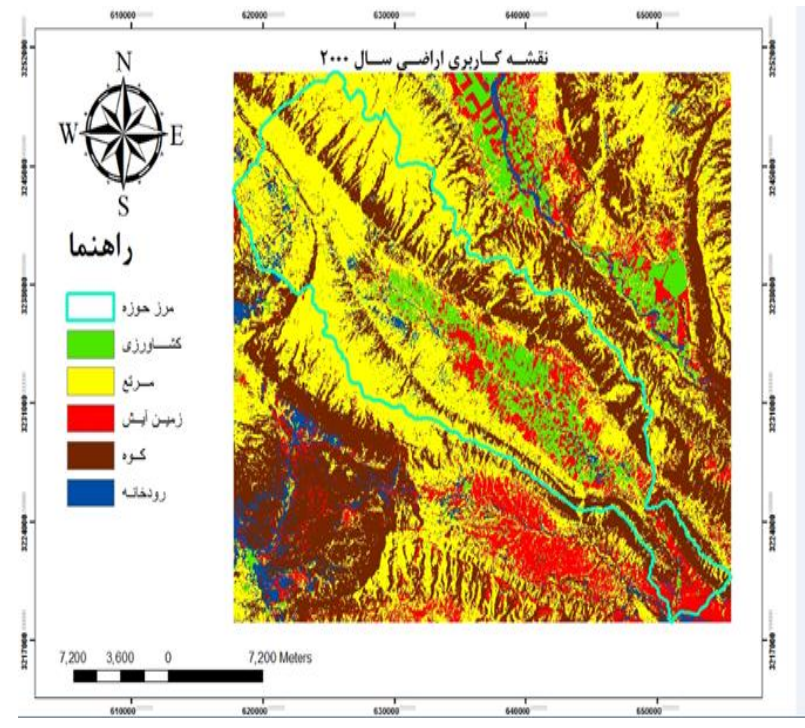

شكل ه- نقشه كاربرى اراضى حوزه آبخيز حنيفقان فيروزآباد فارس در r.... سال حال

Figure 5. Land use map of the Honifaqan watershed of Firouzabad Fars in 2000

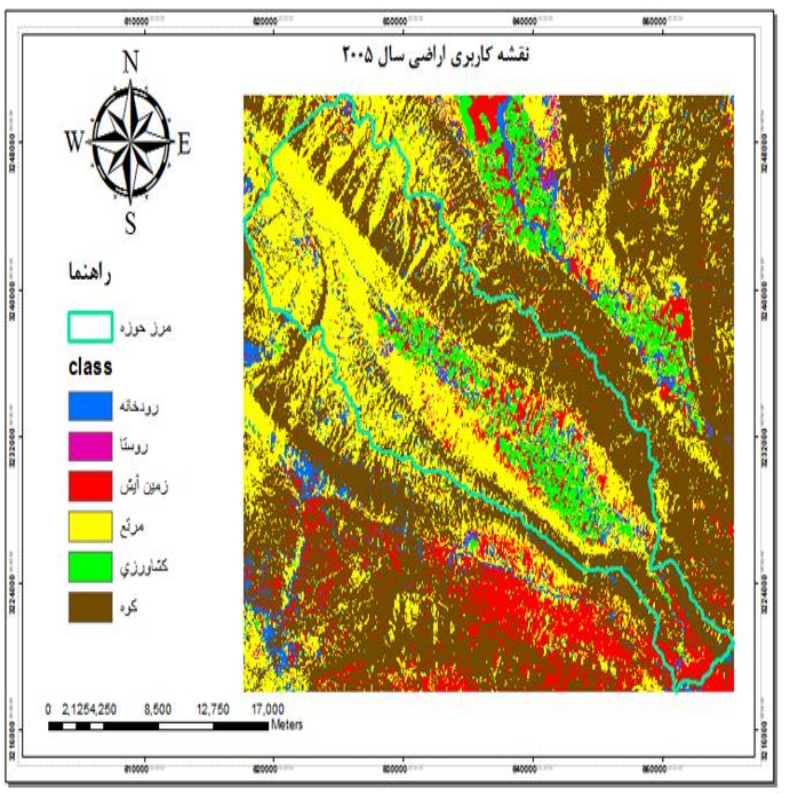

شكل V- نقشه كاربرى اراضى حوزه آبخيز حنيفقان فيروزآباد فارس در

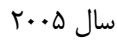

Figure 7. Land use map of the Honifaqan watershed of Firouzabad Fars in 2005 
r)

يزوهشنامه مديريت حوزه آبخيز سال دهم/ شماره • r/ ياييز و زمستان 1هسا
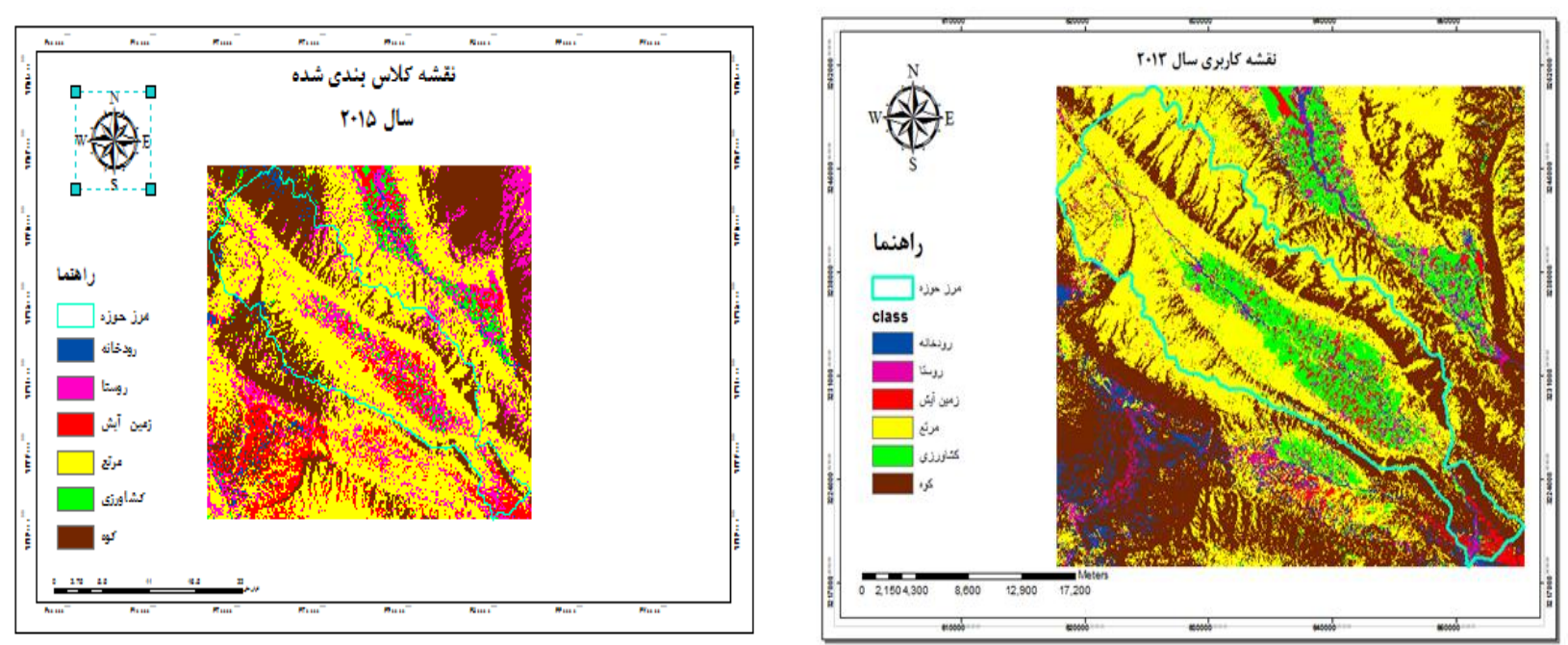

شكل • 1- نقشه كاربرى اراضى حوزه آبخيز حنيفقان فيروزآباد فارس در

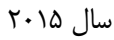

Figure 10. Land use map of the Honifaqan watershed of Firouzabad Fars in 2015
شكل q- نقشه كاربرى اراضى حوزه آبخيز حنيفقان فيروزآباد فارس در سال سו r.

Figure 9.Land use map of the Honifaqan watershed of Firouzabad Fars in 2013
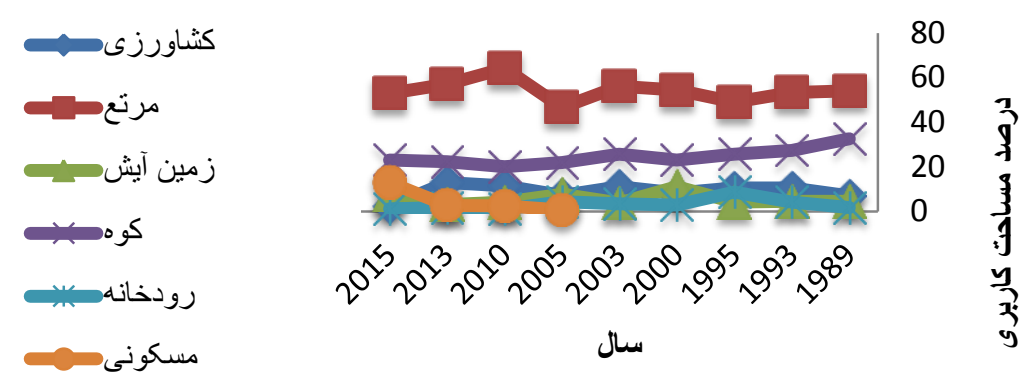

شكل II - روند تغييرات درصد مساحت كاربرى اراضى در دورههاى زمانى مطالعه شده

Figure 11. The trend of changes in the percentage of land use in the studied periods

درصد مساحت حوزه را تشكيل مىدهد از حالت متراكم به

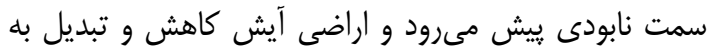

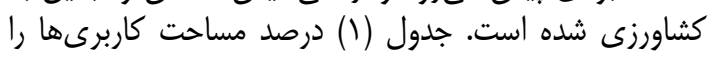

$$
\text { نشان مى نـاورى نده. }
$$

همانطور كه در شكل (r) تا (·) (1) و (11) مشاهده

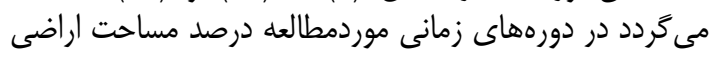
كشاورزى كاهش و درصد درد مساحت اراضى موردى مسكونى افزايش

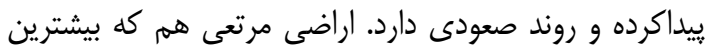

Table 1. Percentage area of use in the years under review

\begin{tabular}{|c|c|c|c|c|c|c|c|}
\hline$r \cdot 10$ & $r \cdot 1$. & $r \cdots \Delta$ & $r \ldots$ & 1990 & 1994 & 1919 & \\
\hline$r / r q$ & $11 / 4 q$ & $\mathrm{~V} / \mathrm{Mr}$ & $1 /{ }^{\prime} q$ & $\mid r / F \lambda$ & $1 . / 4 V$ & $V / 1$ & كشاورزى \\
\hline$V / D)$ & $r / r \Lambda$ & $V / F V$ & $11 / 11$ & $r / r$ & r/gr & $|c| q \mid$ & زمين آيش \\
\hline$r / \cdot V$ & r. & $r m / \cdot V$ & - & - & - & - & مسكونى \\
\hline $1 \ldots$ & $1 \ldots$ & $1 \ldots$ & $1 \ldots$ & $1 \ldots$ & $1 \ldots$ & $1 \ldots$ & كل \\
\hline
\end{tabular}


معادله، مساحت مربوط به هريك از كاربرىها در سال

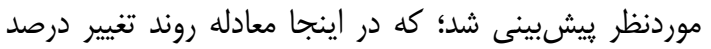

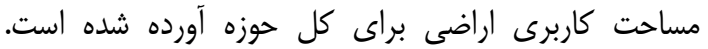

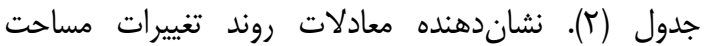

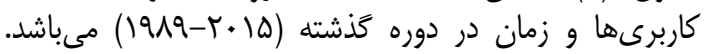

آتى احى سناريو و ييشبينى كاربرى اراضى سالهاى جهت آتَاهى از وضعيت كاربرى اراضى سالهاى آتى بعد آتي

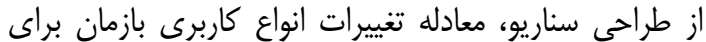

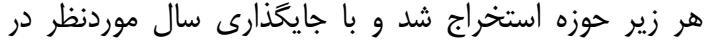

جدول r- معادلات روند تغييرات مساحت هريك از كاربرىها در طول زمان Table 2. Equations of trend of changing the area of each land use over time

\begin{tabular}{|c|c|}
\hline روابط مساحت كاربرى و زمان & نوع كاربرى \\
\hline$Y=-r \mu / \Delta \Lambda x+\Delta .9 r \Lambda$ & كشاورزى \\
\hline$Y=V T / V \Delta x-|T F \cdot Y|$ & مرتع مرت \\
\hline $\mathrm{Y}=s / r \Delta \mathrm{x}-1 \cdot r q \Delta$ & زمين آيش \\
\hline $\mathrm{Y}=\mid f / g r \Delta x-r q T \Delta T$ & اراضى مسكونى \\
\hline 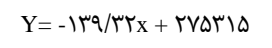 & كوه \\
\hline$Y=-\Delta \cdot 1 \cdot \Delta x+1 \cdot|\Delta F|$ & رودخانه \\
\hline
\end{tabular}

مىدهد كه با تغيير كاربرى از سال 1919 تا ها +r بر مقار مقار

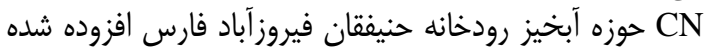

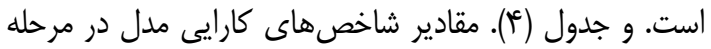
اعتبارسنجى را نشان مى دهد. مقدير

\section{تعيين شماره منحنى كاربرهاى مورد بررسى}

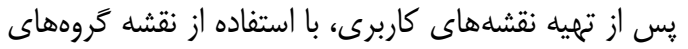

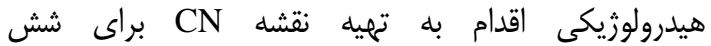

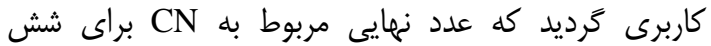

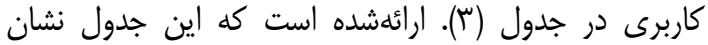

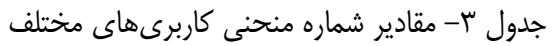

Table 3. The values of Curve Number in different land uses

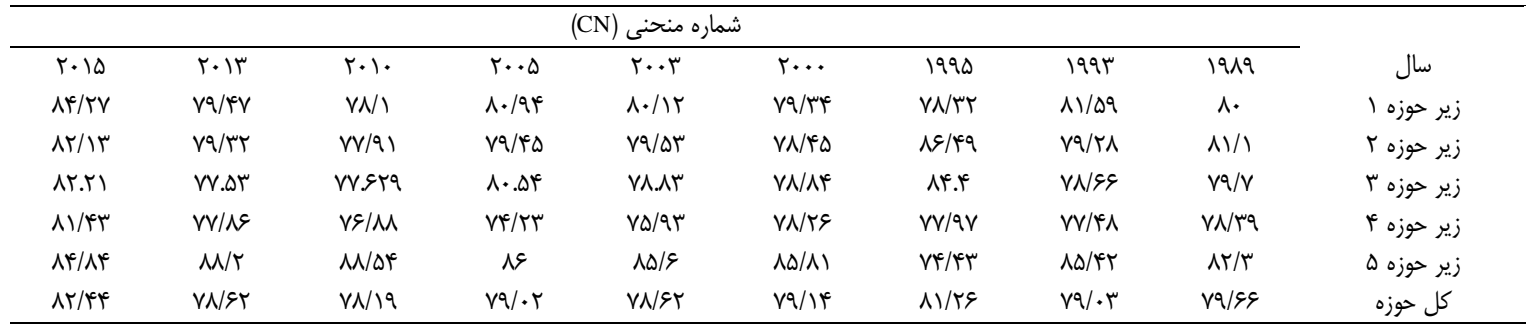

جدول ع - مقادير شاخصهاى كار ايى مدل در مرحله اعتبارسنجى

Table 4. The values of performance indicators of the model at the validation stage

\begin{tabular}{|c|c|c|c|c|}
\hline \multicolumn{4}{|c|}{ مقدار كارايى مق } & \multirow[t]{2}{*}{ 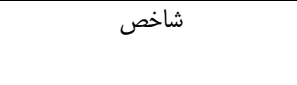 } \\
\hline $\mid r q r / \cdot 1 / 11$ & $1 \mathrm{MN} / \cdot 9 / \mathrm{V}$ & $\mid r N \Delta / \cdot 9 / r \varepsilon$ & $\mid r \wedge r / \cdot q / 1 D$ & \\
\hline 191 & 191 & 194 & 198 & ضريب ناش - ساتكليف \\
\hline$-/ / r$ & $-l \cdot V$ & $-/ / \mu$ & $-11 \Lambda$ & اريبى مدل در برآورد حجم جريان \\
\hline $9 / \mu 1$ & $V / \& q$ & $1 T / \Delta$ & $9 / 9)^{2}$ & درصد خطا در دبى اوج \\
\hline l.r & $1 \cdot 1$ & $1 \cdots 1$ & $1 \cdot 1$ & ميانگَين حداقل مربعات خطا \\
\hline
\end{tabular}

اين مرحله از تحقيق با درنظرگرفتن تغييرات CN

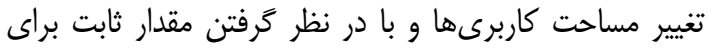

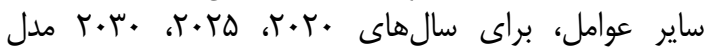
براى رخداد مورخ HEC-HMS

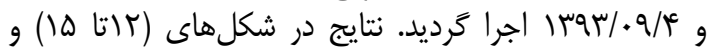
جداول (ه تا V) ارائه شده است.
تغييرات دبى در دورههاى آينده تحت تأثير

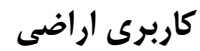
تغييرات دبى بستخى به موارد زيادى ازجمله خصوصي

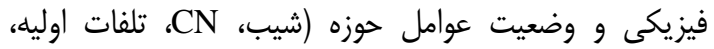

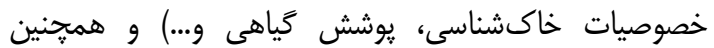
خصوصيات جوى (تغيير درشدت، ميزان و نوع بارش) دارد. در 


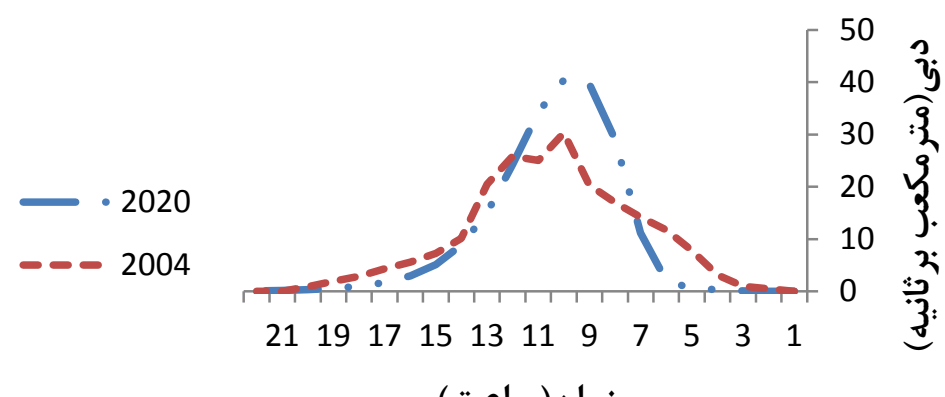

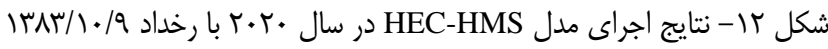

Figure 12. Results of the implementation of the HEC-HMS model in 2020 with the storm of 30/12/2004

Table 5. Results of HEC-HMS model implementation in 2020 with storm of 30/12/2004

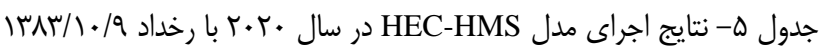

\begin{tabular}{|c|c|c|c|}
\hline درصد اختلاف & T.r. & $r \ldots y$ & مإرامتر \\
\hline$\Delta \Gamma / \Lambda$ & 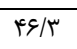 & $\Gamma \cdot / \mu$ & دبى اوج (مترمكعب بر ثانيه) \\
\hline$r \cdot / 4)$ & $9.1 / r$ & $V E N / F$ & حجم سيل (هزار مترمكب) \\
\hline
\end{tabular}

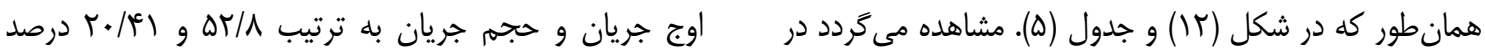

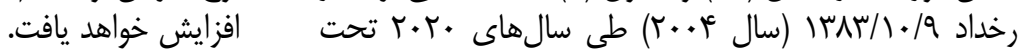
تأثير تغيير كاربرى اراضى و به تبع آن افزايش مقدار سار

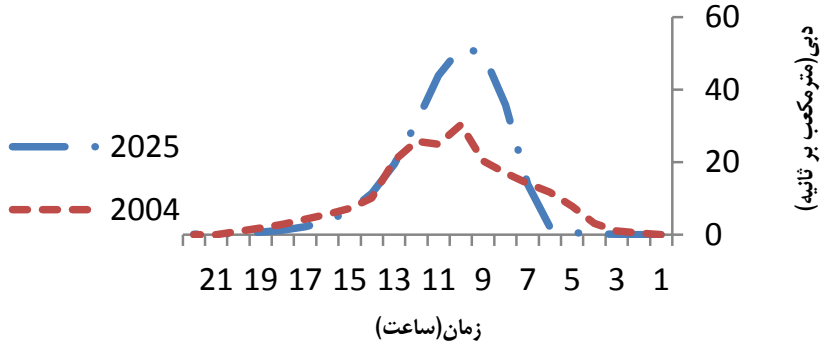

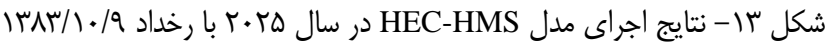

Figure 13. Results of the implementation of the HEC-HMS model in 2025with the storm of 30/12/2004

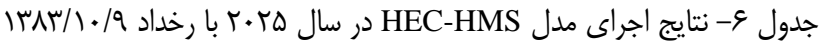
Table 6. Results of HEC-HMS model implementation in 2025 with storm of 30/12/2004

\begin{tabular}{|c|c|c|c|}
\hline درصد اختلاف & $r \cdot r \Delta$ & r..re & هيارامتر \\
\hline$v \cdot / r q$ & Q1/9 & $r \cdot / r$ & دبى اوج (مترمكعب بر ثانيه) \\
\hline$M Y / Q 1$ & $99 / / \wedge$ & $V N^{N} N / A^{4}$ & حجم سيل (هزار مترمكعب) \\
\hline
\end{tabular}

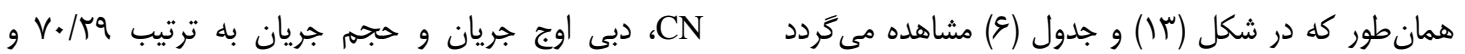
در رخداد

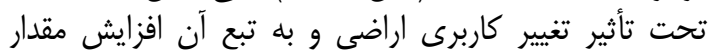

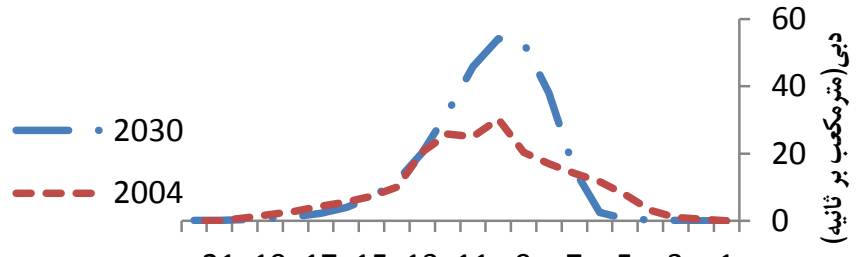

$\begin{array}{lllllllllll}21 & 19 & 17 & 15 & 13 & 11 & 9 & 7 & 5 & 3 & 1\end{array}$

زمان (ساعت)

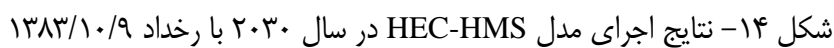

Figure 14. Results of the implementation of the HEC-HMS model in 2030 with the storm of 30/12/2004 


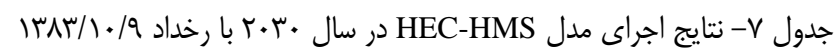
Table 7. Results of HEC-HMS model implementation in 2030 with storm of 30/12/2004

\begin{tabular}{|c|c|c|c|}
\hline درصد اختلاف & T.Y. & $r .+r$ & يّارامتر \\
\hline$V N / A V$ & $\Delta F / T$ & $r \cdot / r$ & دبى اوج (مترمكعب بر ثانيه) \\
\hline$\Gamma N \cdot \Delta$ & $1 . \kappa 4 / 8$ & $V Q S / T$ & حجم سيل (هزار مترمكعب) \\
\hline
\end{tabular}

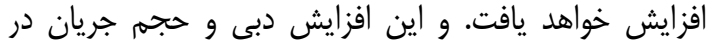

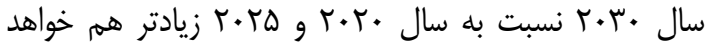

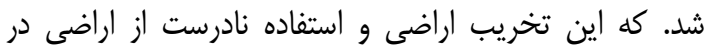

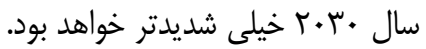

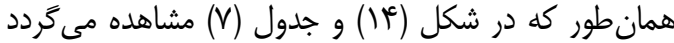

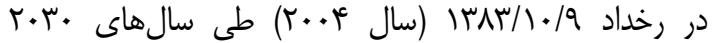
تحت تأثير تغيير كاربرى و به تبع آن افزايش مقدار

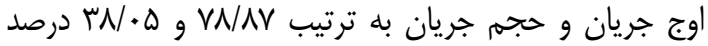

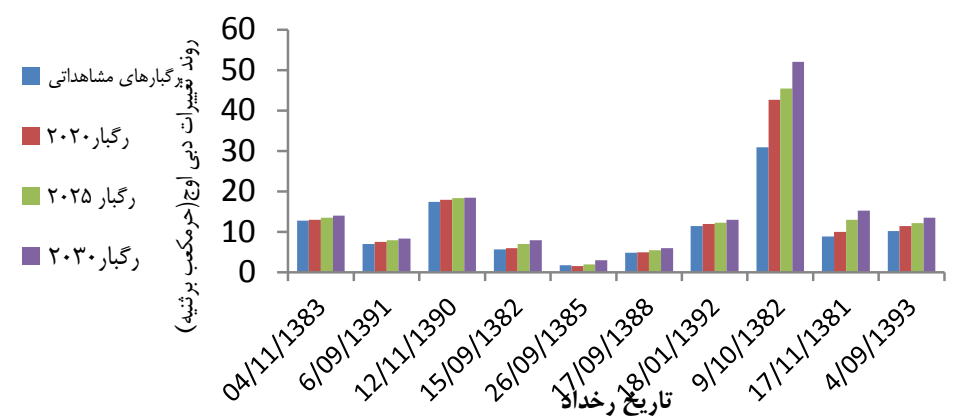

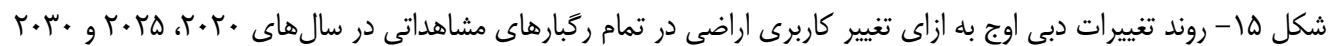

Figure 15. Changes in peak flow rate due to land use change in all obsereved storms in 2020, 2025, and 2030

تغييرات رسوب در آينده

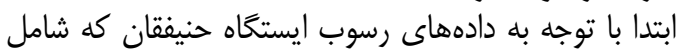

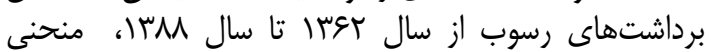

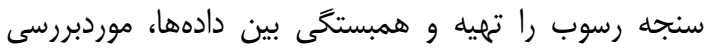

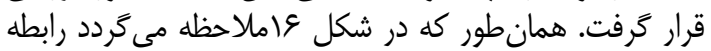

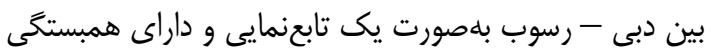

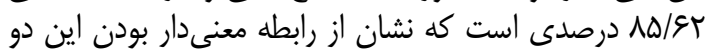

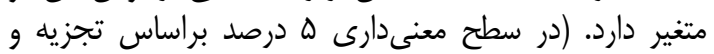

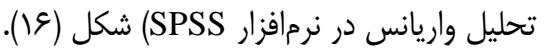

همان طور كه در شكل (D) مشاهده مى مَردد در تمام

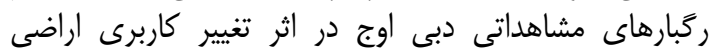

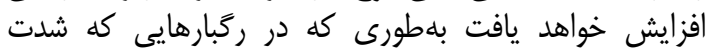

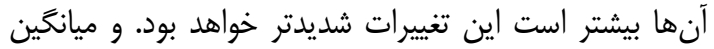

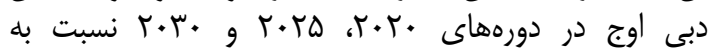
ميانغين دبى اوج ركبارهاى مشاهداتى (در اثر تغيير كاربرى دونى

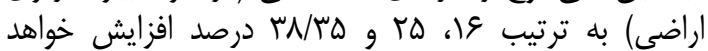
يافت.

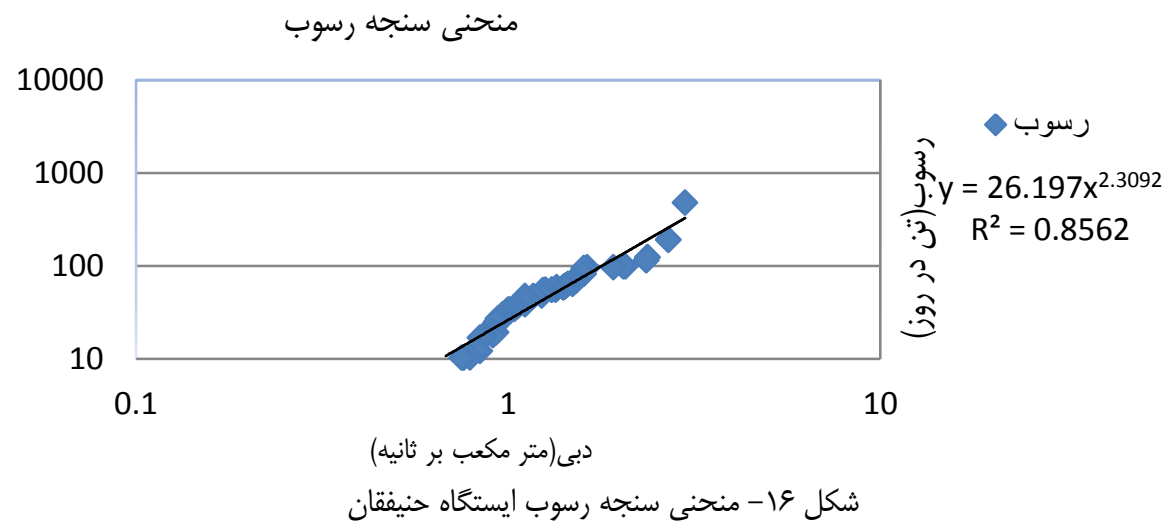

Figure 16. Sediment rating curve in Honifaqan station

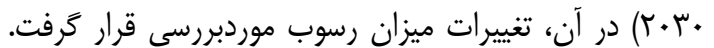

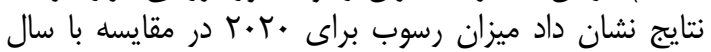

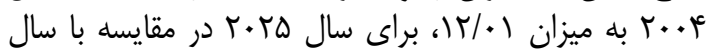

بلهرحال تعيين تغييرات رسوب در آينده با استفاده از

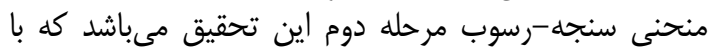

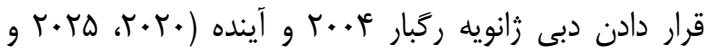




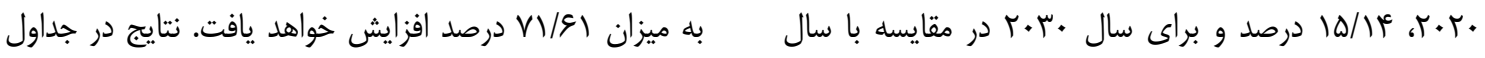

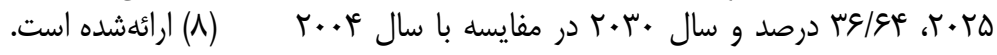

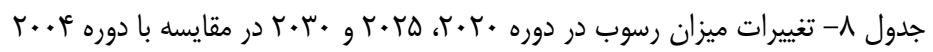
Table 8. Change of sediment rate in the period of 2020, 2025 and 2030 compared to the 2004 period

\begin{tabular}{|c|c|c|c|c|c|}
\hline درصد تغييرات & $r \cdot r \cdot$ & $r \cdot r \Delta$ & $r \cdot r \cdot$ & $r \cdots r$ & سال \\
\hline$V(q / 9)$ & $\Delta f^{c}$ & $\uparrow \mathcal{N} / \uparrow^{\leftarrow}$ & $F \Delta / \&$ & $r \cdot / \mu$ & دبى (مترمكعب بر ثانيه) \\
\hline$\Lambda V / \Lambda$ & 1MVI/.人 & IEqETा/10 & $|f V \pi \| /| q$ & gGart/I & رسوب (تن در روز) \\
\hline
\end{tabular}

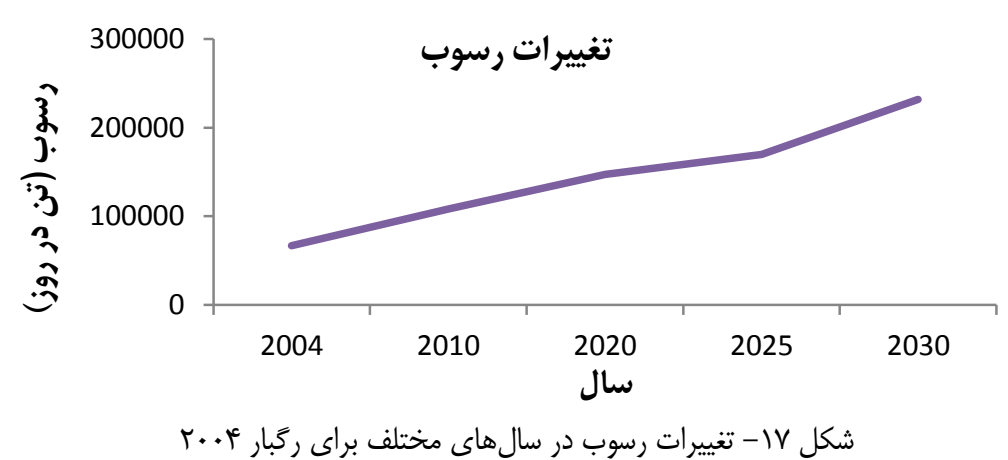

Figure 17. Sediment variations in different years for rainfall 2004

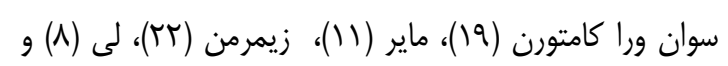
على و همكاران (T) همخوانى دان دارد.

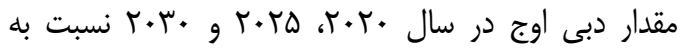

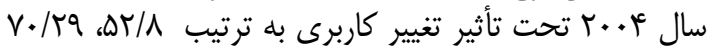

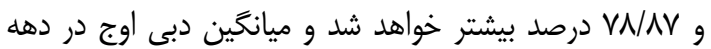

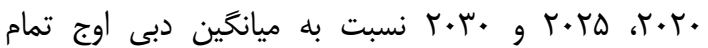

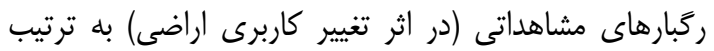

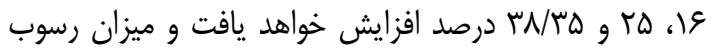

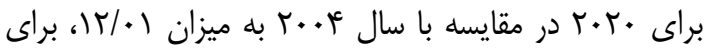

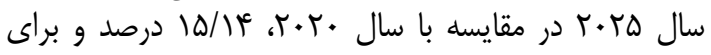

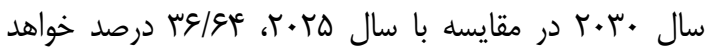

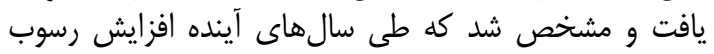

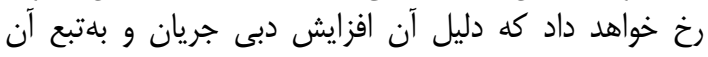
افزايش حجم سيلاب و افزايش رسوبكذار در حوزي حرن خواهد
همانطور كه در شكل (IV) مشاهده مى كردد طى سالهاى

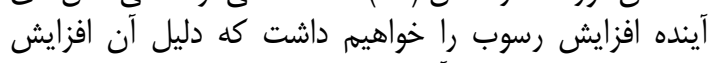

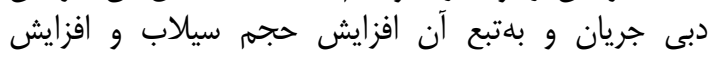
رسوب كذار در حوزه است.

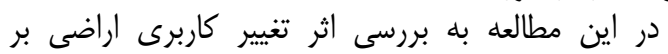

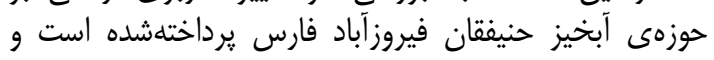

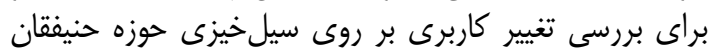

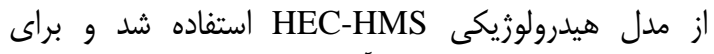
بررسى تغييرات رسوب در آينده از منحنى سنجه رسوب

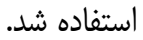

نتايج تحقيق حاضر نشان مىدهد كه تغيير كاربرى اراضى داضى دان

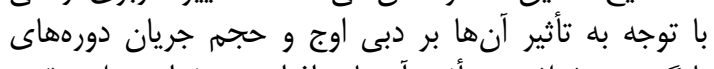

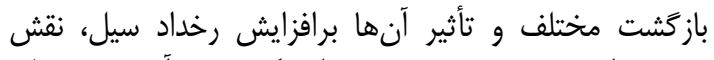

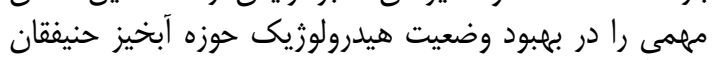

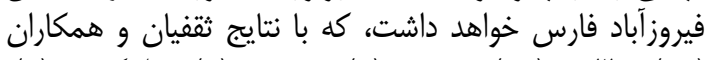

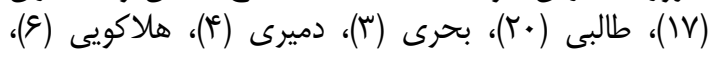


1. Abbaszade Tehrani, N., D. Makhdoom and M. Mahdavi. 2009. Tasyyr review of land use change on the flood by using remote sensing and GIS. Environmental Studies, 1(2): 78 pp (In Persian).

2. Ali, M., S. Jamal Khan, L. Aslam and Z. Khan. 2011. Simulation of the impacts of land-use change on surface runoff of Lai Nullah Basin in Islamabad Pkistan. Landscape and Urban Planning, 102(4): 30 pp.

3. Bahri, M. 2013. Assess the impact of climate change and land use change on hydrologic watershed reactions. The Ninth National Congress of Watershed Management Science and Engineering (In Persian).

4. Damir, C. and C. Karimzadeh. 2011. Land use change and its effect on surface runoff and groundwater fluctuations (Case Study of Dry River Shiraz). Watershed Master's thesis. Faculty of Natural Resources, Tehran University (In Persian).

5. Ghaffari, G., C. Holy and H. Ahmed. 2008. Evaluation of land use change on the hydrological response of the watershed (Case Study: Zanjan River watershed). Journal of Water and Soil Conservation Volume XVI No. 1 (In Persian).

6. Hallakoui, M., A. Talebi and H. Mlkynzhad. 2011. Evaluation of land use change and its effect on surface runoff. Chehel-Chai watershed precipitation, watershed management master's thesis, Faculty of Natural Resources, Yazd University (In Persian).

7. Jandaghi, M. and M. Baghani. 2007. Evaluation of land use changes on flood regime catchment areas of small (approximately hill Gorgan watershed case study). River Engineering Seminar 2007, University of Ahvaz (electronic version of the Proceedings of the Conference) (In Persian).

8. Li, K., Y. Coe, M.T. Ramankutty and R. De Jong. 2007. Modeling the hydrological impact of land use change in West Africa. Journal of Hydrology, Volume 337, Issues 3-4, 30 April 2007, pp: 258-268.

9. Lorup, J.K., J.C. Refsgaard and D. Mazimavi. 1998. Assessing the effect of Land use change on catchment runoff by combined use of statistical tests and hydrological modeling: case studi from Zimbabwe, Journol of hydrology, 205, pp: 147-163.

10. Mahmoodzadeh, A. 1997. Investigating the relationship sediment production and land use. Journal of forest and pasture. No 36, pp: 30-25.

11. Meyer, W.B. and B.L. Turner.II 1996. Land -use/ Land-Cover Cgehan: Challenges for Geographers."Geojournal, 39(3): 237-240.

12. Mirzaii, S., H. Zainivand and A. Haghizadeh. 2017. Simulation of Daily Suspended Sediment and Investigation of the Impact of land Use Change in GolGol Watershed, Ilam. Journal of Watershed Management Research, 7(14): 59-48 (In Persian).

13. Mostafasolyman, W.G. Kepner and M.H. Mehaffey. 2015. Integration landscape assessment and hydrologic modeling for land cover change analysis. Journal of the American water resources association, 38(4): 919-929.

14. Rafieian, M. and D. Mhmvdy. 2010. Patterns of land use change analysis and theoretical modeling approach, published by lightning (In Persian).

15. Rahmani, N., K. Shahedi, K. Soleimani and M. Yaqobzadeh. 2016. Evaluation of the Land use Change Impact on Hydrologic Characteristics (Case Study: Kasilian Watershed). Journal of Watershed Management Research, 7(13): 32-23 (In Persian).

16. Sadeghi, S.H.R. 1995. The causes of floods and evaluation of factors affecting Qablkntrl. Forest and Rangeland Journal, Issue 26 (In Persian).

17. Saghafian, B., H. Ascendent, A.S. Sepehr and A.S. Najafinejad. 2006. The effect of land use changes on SylKhyzy Golestan dam catchment area. Iranian Journal of Natural Resources, Issue 1, pp: 18-28 (In Persian).

18. Shi, Z., H. Zhang, P.C. Fang and N.F. Yan. 2013. Impacts of Landuse change on watershed streamflow and sedimentyild: An assessment using hydrologic modeling and partial least squares regression. Journol of hydrology, 484: 26-37.

19. Suwanwerakamtorn, R. 1994. GIS and hydrobbgic modelling for management of small watersheds. ITC Joornol, No. 4, pp: 343-349.

20. Talebi, A., F. Svzndhpvr and A. Karimiyan. 2015. The effect of land use on current conditions and the amount of sediment yield optimization, Journal of Soil and Water Sciences, Isfahan University of Technology (In Persian).

21. Zare, I. 2015. Study of climate change on discharge and sediment dam catchment means of Mashhad, a master's thesis. Department of natural resources. Yazd University (In Persian).

22. Zimmermann, L. 2006. The influence of land use changes on soil hydraulic properties implications run off generation. Forest Ecology and Management, Volume 222, Issues 1-3, 15 February 2006, pp: 29-38. 


\title{
Investigation of the Effects of Land Use Change on Flooding and Sedimentation In Honifaqan Watershed
}

\author{
Ali Talebi ${ }^{1}$, Mehrnaz Shahrivar ${ }^{2}$, Hossein Malekinezhad ${ }^{3}$, Samaneh Poormohamadi $^{4}$ \\ and Zeinolabedin Hosseini ${ }^{5}$
1- Professor, Faculty of Natural Resources and Desert ology, Department of Rangeland and Watershed Management, Yazd University (Corresponding author: talebisf@yazd.ac.ir) 2- M.Sc. student, Yazd University
3 and 5- Assistant Professor and associate Professor, Faculty of Natural Resources and Desertology, Department of Rangeland and Watershed Management, Yazd University
4- Researcher, Cloud Fertility Research Center
Received: June 22, $2017 \quad$ Accepted: June 19, 2019

\begin{abstract}
In a natural ecosystem, land exploitation and change in environmental conditions, particularly changes in vegetation and land use have effects on hydrological responses such as floods and erosion and sediment and ultimately causing heavy social-economic losses. Then, prediction of effect of land use changes on flood situation in the future decades and sedimentation of watersheds will be the way of dealing with this phenomenon. To simulate the hydrological behavior in future decades, HEC-HMS model was calibrated and validated for the previous period, with changes in curve number and percentage of impermeability (as a result of land use changes). Then, predicted hydrograph for coming decades (2020, 2025 and 2030) and last (2004) were compared. The results show that the peak discharge and flood volume in the 2020, 2025 and 2030, will be increased in compared to the decade of 2004 equal to (52.8 and 20/41), (70.29 and 32.51) and (87.78 and 38.05), respectively will increase. Mean peak in the 2020, 2025 and 2030 will be increase (due to land use change), 16, 25 and 38.35 percent, respectively. In the next step, sediment changes in the future was investigated using the sediment rating curve in decades of 2020, 2025 and 2030. The results showed that the amount of sediment for 2020 will be increase $12.01 \%$ compare to 2004, for 2025 compare to 2020, $15.14 \%$ and for 2030 compare to $2025,36.64 \%$. According to the results, land use change in future leads to increase in discharge and sediment, which could affect the hydrological and morphological conditions of watershed.

Keywords: Calibration, Erosion, HEC-HMS, Land Use Change, Runoff, Sediment Rating
\end{abstract} Curve 